Bulletin de la Société Royale des Sciences de Liège, Vol. 85, 2016, p. 215 - 226

\title{
DSP-BASED INTEGRATED CONTROL MODELING AND IMPLEMENTATION OF NONINVERTING BUCK-BOOST CONVERTER
}

\author{
Mohsen KARIMI ${ }^{1}$, Adib AbrishamifAR ${ }^{2}$, Mehdi FAZELI ${ }^{3}$ \\ ${ }^{1}$ Electrical Converter \& Power system ,Dept., IRIEE, ACECR Tehran, Iran,- \\ Karimi.fsk@gmail.com-corresponding author \\ ${ }^{2}$ Department of Electrical and Electronics Engineering, Iran University of Science and Technology, \\ Abrishamifar@iust.ac.ir \\ ${ }^{3}$ Electrical Converter \& Power system,Dept., IRIEE, ACECR Tehran, Iran,m.Fazeli@jdves.com
}

\begin{abstract}
The authors propose a new hybrid control system for digital implementation of a positive buck-boost DC-DC converter, based on DSP controller, high voltage regulating, and current integral loop controller for elimination of ripple inductor. This method is predicated on the theory of integrated dynamic system in which the inputs (Vin\& Iin) and high loads of positive DC-DC converter is continuous and output as a discontinuous mode in lower loads. Therefore the system of the converter is accomplished by combination of two different characteristics of a dynamic modeling: a) Proper selection of the converter state variables, b) Average of inductor current and output errors that correspond to design and implementation of experimental system. Different load and input voltage variation conditions are simulated in MATLAB/SIMULINK and implemented in DSP controller and all of the results indicate the controller to verify the suitability designed controller. The simulation and experimental result on positive buck-boost DC-DC converter is found to be satisfactory.
\end{abstract}

Keywords: Positive buck-boost DC-DC converter, Integrated control system, DSP controller

\section{Introduction}

The Positive DC-DC topologies have been mostly used in industrial applications such as uninterruptible power supply (UPS), wind turbine and solar power plant, etc. The source energy could be changed in operation mode like battery during discharge or charge mode or rectifier when supplied power of the inverter or the other user can be greater than(buck operation), equal to(buckboost operation), or less than(boost operation) the output voltage. However, for such applications, it is a very important advantage to regulate the output voltage of the converter with high accuracy and efficiency. Due to its unique performance, a trade-off among cost, output ripple or disturbance, low inductor ripple and switch losses, and small inductor size, the positive buck-boost converter has been proposed [1-3].

Basically, the control system for DC-DC converters has been analog control. In the past years, technology advances in very-large-scale integration have made digital control of DC-DC converters with the digital signal processors (DSP). Digital controllers enable the use of advanced control methods which can improve the converter performance in a number of ways. First, the feedback 
and feed forward control laws can be adaptively tuned to optimize system performance. Second, adaptive mode control can be used to maximize efficiency over a wide range of loading conditions and component tolerances. Finally, DSPs have more computational power than microcontrollers. Therefore, more advanced control algorithms can be implemented on a DSP. The implementation of soft-start control, modbus protocol for monitoring arrays and control panel, management of fault protection is far more flexible and often simpler in digital-based control than the analog controller.

Fist problem of control design is: The small signal models for the DC-DC converters change due to variations in operating point. The small signal of the boost operation is a nonlinear function of the operating point, and in the buck operation the magnitude small signal moves, along with the displacement of operating point [1]. The linear controllers were designed only for the nominal operating point, due to distortion inductor current and ripple of voltage and the existence of multiple steady-state stability response of the system is affected, which may cause instability [2]. To solve these problems proposed different topology of controller such as:
a) Feedback linearization control [3], [4].
c) Sliding- mode control [2-5].
b) Passivity-based integral control [4]
d) Back stepping control [7-8].

Second: Most research on these topologies of dc-dc converter has been limited to continuous time and distributed frequency switching to pulse width-modulation (PWM) in different dynamic states. Because infinitely fast switching of the control action is impossible in practice, chattering always occurs in steady state. A constant switching frequency can't be guaranteed. These often perform unacceptably in high load. This causes voltage ripple at the input of converter, which effects the process of controller [1-10]. Third: This issue has prevented the using large filter capacitor at the input of dc sources cannot be considered as an economic solution, that the controller should be designed to have less than $1 \%$ ripple at output and input voltage, low distortion inductor current and high performance in fast transient response of output voltage.

Finally, the control problem of positive buck-boost topology is the changing transition between buck and boost mode operation. For solving this problem is to compare the magnitudes of input and output voltages [8]. The last few papers have evidenced in the method of modeling and control of these converters [2]-[10]. However, The essence of the high power converters are highly nonlinear, discontinuous operating, variable input voltage and output power due to dynamic stability and non-minimum phase system because the zero dynamics of output voltage has become instability[3]-[6]. Already the controller has been designed by improving the zero position which is inversely proportional to the ripple inductor current, in the frequency domain. The zero position of this system is inversely proportional to the ripple inductor current. the response of converter has 
tended toward zero as time in the RHS (right-hand-side), main causing phase lag, which, in turn, limits the available bandwidth for the stability of the converter.

This paper is proposed a new integrated control model with inner loop for reducing ripple of inductor current and outer loop for regulating the output voltage in a positive DC-DC converter [7]. Accordingly, this method reduced dynamic error at the converter's input (the large current ripple). Therefore, for optimizing output dynamic system of converter we are proposed the two control switching regulators: 1) voltage-mode control and 2) current-mode control. Dual loop control for DC-DC converters consist an inner current control is usually considered superior to voltage loop, due to lower current ripple, lower input voltage ripple and improved stability margin certain by the inner current loop according to the positive DC-DC converters analyzing a right-hand-side zero in the transfer function between duty-cycle and output voltage [10-17]. This paper is organized as follows: Section II analysis the producing the positive buck-boost DC- DC converter model, section III Steady state characteristics of the large and small signal models, IV applies the integrated digital dual controller implementation of a positive DC-DC converter system operating in DSP Texas Instruments. The simulation and experimental results are compared and presented in section $\mathrm{V}$, The last section VI, the conclusion is summarized.

\section{The non-inverting buck-boost DC- DC converter}

The positive buck-boost converter is supplying source voltage to higher and lower voltage by changing mode operation. The positive buck-boost DC-DC converter as shown in Fig 1.

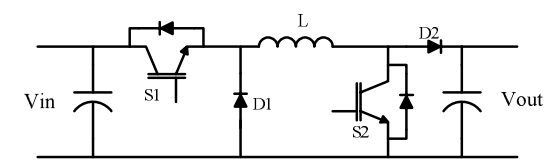

Fig 1.The positive buck-boost converter configuration

The operation of converter is when the input voltage is lower than output voltage, converter change as a boost mode therefore the switch $\mathrm{S} 1$ is close and the switch S2 transient's energy by controlling pulse width modulation (PWM). When the input voltage is more than the output reference voltage, converter operates as a buck converter, therefore the switch S1 transients energy by controlling PWM and the switch S2 is open, can reduce the switching loss. However, the complex control logic and compensation technique are needed to enable the two working modes to transfer smoothly. So operating of converter is delivered that the transient output of the converter is always positive. 
CCM operation: The operation waveform in the positive converter control strategy when $\mathrm{V}_{\text {ind }} \mathrm{dc}>\mathrm{V}_{\text {out }} \mathrm{dc}$ and high loads is shown in Figs. $2 \mathrm{a}$ and b. The operators in CCM of the converter are shown in Figs. 3. At time period t2, S1, S2 are turned ON and D1, D2 are turned OFF, and inductor

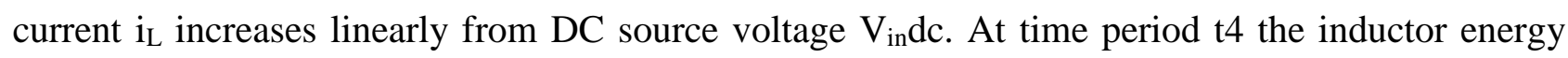
discharge to the capacitor $\mathrm{C}_{\mathrm{dc}}$ and to the load.

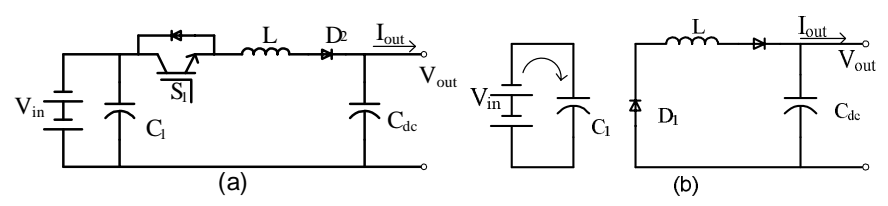

Fig. 2a. Equivalent circuits of converter when $S_{1}=\mathbf{P W M}$ and $S_{2}$ off in the buck mode Fig. 2b. Equivalent circuits of converter when $S_{1}$ and $S_{2}$ off in the buck mode when $L$ is discharged

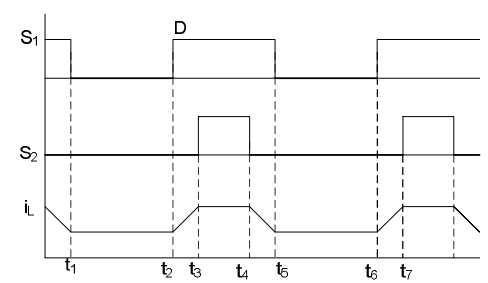

Fig .3. Key waveforms under CCM operation at $t_{0}$

DCM operation: When $\mathrm{V}_{\text {in }} \mathrm{dc}>\mathrm{V}_{\text {out }} \mathrm{dc}$ (show in Fig.4a), the switches $\mathrm{S} 1$ are turned ON and S2 turned OFF at the same time. At $t_{2}$ when $V_{\text {ind }} d c<V_{\text {out }} d c, S_{1}$ has always been ON and $S 2$ is turned PWM (shown in Fig.4 (b) and (c)). In this mode operation, inductors L store energies from source

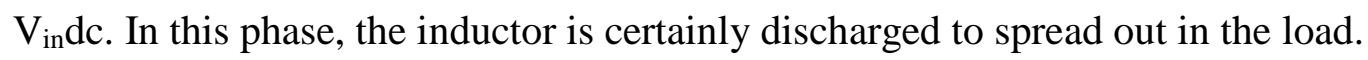

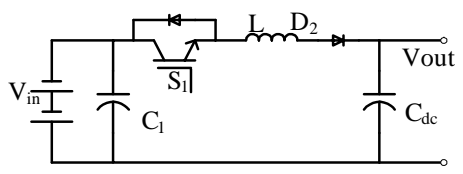

(a)

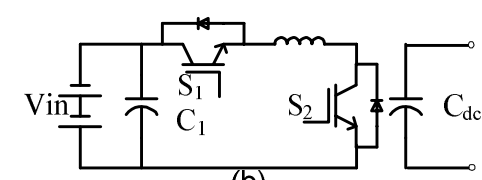

(b)

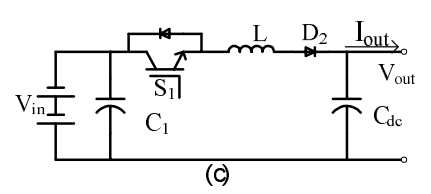

(C)

Fig . 4a. Equivalent circuits of converter when $S 1=P W M$ and $S_{2}$ off in the Buck mode

Fig 4b. Equivalent circuits of converter when $\mathrm{S} 1=\mathbf{O N}$ and $\mathrm{S} 2=\mathbf{P W M}$ in boost mode when $\mathrm{L}$ is charged

Fig.4c. Equivalent circuits of converter when $\mathrm{S} 1=\mathbf{O N}$ and $\mathrm{S} 2=\mathbf{P W M}$ in boost mode when $\mathrm{L}$ is discharged

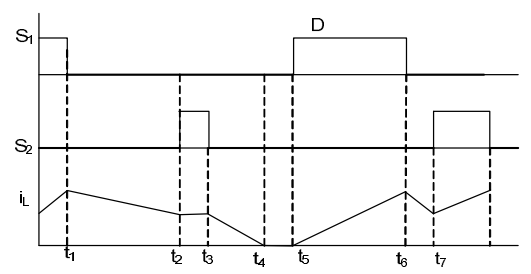

Fig.5. Key waveforms under DCM operation at $\mathrm{t}_{2}$ Buck-Boost 
Inductor current $i_{\mathrm{L}}$ Fig 5 at the time $\mathrm{t} 2$ increases linearly, and at $\mathrm{t} 3 \mathrm{i}_{\mathrm{L}}$ decreases to zero during part of switching cycle, when it change from CCM to DCM. In this mode, inductor current $\mathrm{i}_{\mathrm{L}}$ decreases linearly. The load is supplied by capacitor $\mathrm{C}_{\mathrm{dc}}$ and inductor $\mathrm{L}$.

According to output power, the converter must be supplied wide range of output load power, as low load the converter operates in the DCM, or as high load the converter operates in the CCM. If the converter is in buck mode and operates on middle loads, the current controller works at the beginning and at the end of the half cycle in DCM. Otherwise, in boost mode the current controller works at the middle of the half cycle in CCM.

\section{Steady State characteristics in the Large and Small Signal Modeling}

Before The positive converter with two switches is shown in Fig. 3a, which can operate as a buck by switch S1\&D1 and also work as a boost converter by switch S2\& and in the middle voltage converter operate as buck-boost mode by $\mathrm{S} 1 \& \mathrm{~S} 2$. The steady state transfer function is used large and small signal and analysis based on state space averaging method [3,17]. For these operation modes are defined as follows.

The transfer-functions and DC-gains of buck operation are (1):

$\frac{\tilde{v_{o}}(s)}{d_{\text {buck }}(s)}=\frac{\frac{1}{L \cdot C} \cdot V_{i n}}{s^{2}+\frac{1}{R \cdot C} \cdot s+\frac{1}{L \cdot C}}$

In boost mode operation was divided two modes of operation corresponding to switch S2. When the switch S2 is closed and S1 is ON as shown in Fig 4a, the diode is reverse biased and the input energy stored in the inductor while the capacitor discharges into the load. The dynamic equations of the converter are obtained, the following (2):

$L \frac{d i}{d t}=V_{i n}(t)$

In the second mode operation, the switch $\mathrm{S} 2$ is OFF and $\mathrm{S} 1$ is $\mathrm{ON}$ as shown the Fig.4b, the diode conducts and both energy from the input voltage and energy stored in the inductor are converted to the capacitor and the load, the dynamic equations of the converter are shown as follows(3):

$L \frac{d i}{d t}=V_{\text {in }}(t)-V_{\text {out }}(t)$

Equivalently;

$L \frac{d i}{d t}=V_{\text {in }}(t)-\left(1-D_{\text {boost }}(t)\right) \times V_{\text {out }}(t)$ 
Regarding Laplace method, from the fig. $4 \mathrm{~b}$ and $\mathrm{b}$ output transfer function of open loop power stage is (5):

$$
\frac{\tilde{v}_{O}(s)}{D_{\text {boost }}(s)}=\frac{\frac{\tilde{v}_{O} \cdot\left(1-D_{\text {booss }}\right)}{L \cdot C}-\frac{s I}{C}}{s^{2}+\frac{s}{\mathrm{R} C}+\frac{\left(1-D_{\text {booss }}\right)^{2}}{L C}}
$$

And for buck-boost mode operation, the transfer-functions and DC-gains are (6),(7),(8),(9).

$$
\frac{\tilde{v}_{O}(s)}{D_{\text {buck-boost }}(s)}=\frac{\left(\frac{V_{i n}+V_{o}}{L \cdot C}\right) \cdot\left(1-D_{\text {buck-booss }}\right)-\frac{s I}{C}}{s^{2}+\frac{s}{\mathrm{R} C}+\frac{\left(1-D_{\text {buck-bosst }}\right)^{2}}{L C}}
$$

and therefore

$$
V_{o}(0)=\frac{\left(\frac{V_{i n}}{L \cdot C}\right) \cdot\left(1-D_{\text {buck-boost }}\right)}{s^{2}+\frac{s}{\mathrm{R} C}+\frac{\left(1-D_{\text {buck-boost }}\right)^{2}}{L C}}
$$

Hence

$$
\frac{\tilde{v}_{o}(s)}{D_{\text {buck-boost }}(s)}=\frac{\left(V_{\text {in }}+V_{o}\right)}{\left(1-D_{\text {buck-boost }}\right)}
$$

The output voltage of converter in buck-boost mode is obtained the following:

$$
V_{o}(0)=\frac{D_{\text {buck-boost }} \cdot V_{\text {in }}}{\left(1-D_{\text {buck-boost }}\right)}
$$

In the transition mode operation from buck to buck-boost, the value of duty cycle is changed from 1 to 0.5 , The value of duty cycles $D_{\text {buck }}, D_{\text {boost }}$ and $D_{\text {buck-boost }}$ are related as follows:

$$
D_{\text {buck }}=\frac{V_{\text {out }}}{V_{\text {in }}} \quad D_{\text {boost }}=\frac{V_{\text {out }}-V_{\text {in }}}{V_{\text {out }}} \quad D_{\text {buck-boost }}=\frac{V_{\text {out }}}{V_{\text {out }}-V_{\text {in }}}
$$

The result of comparing duty cycle of each mode operation is shown in Fig. 6.

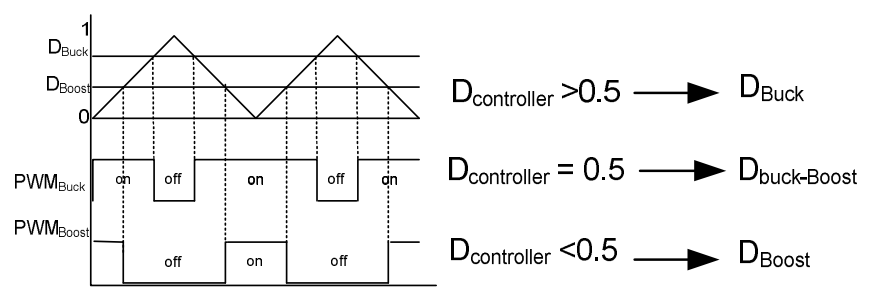

Fig.6. PWM pulse generation 
The bode diagram of converter shows that the phase margin is not enough for stability of converter, Hence the controller must be to increase the phase margin. The problems of designing the controller is that zero of the system limits the bandwidth of loop-control.

The bode diagram of positive buck- boost converter is illustrated on Figure 7.The phase margin of close loop system is about 180 degree, therefore for stability of the closed loop cut-off frequency should be much smaller than pole frequency, so that means the crossover frequency has to choose high for necessary available loop bandwidth, Hence the phase margin can grantee of close-loop system's stability.

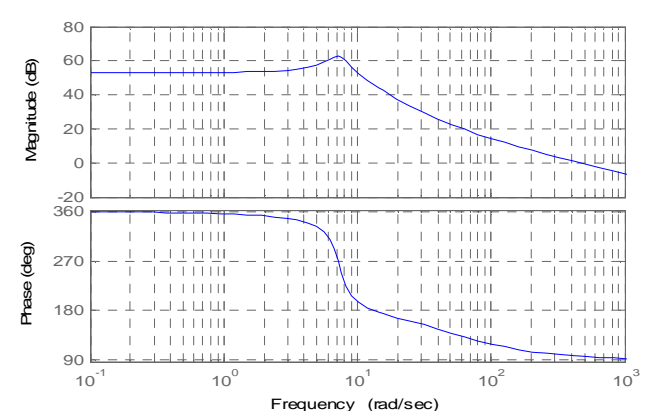

Fig.7. Frequency responses of $\frac{\tilde{v}_{\text {out }}}{D}$

The phase margin of the loop gain should be positive implies that a system is stable. The suitable value of phase margin is $45^{\circ}$ to $60^{\circ}$ corresponding to stability. A proportional-integral (PI) controller is used to increase the low frequency loop gain, thus reducing steady-state error. The transfer function of a PI controller is shown in (10).correspond

$$
G_{P I}(\mathrm{~s})=K_{p}+\frac{K_{I}}{s}
$$

\section{Analyzing Digital controller of the positive buck-boost converter}

Widely, if the sampling frequency of a digital controller is selected to be much higher than the control-loop bandwidth, the digital redesign approach is taken in the design of the digital controller in Fig. 8 since according to sampling frequency $30 \mathrm{kHz}$ is much faster than the switching frequency that is well below $\mathrm{f}_{\mathrm{sw}}=15 \mathrm{kHz}$.

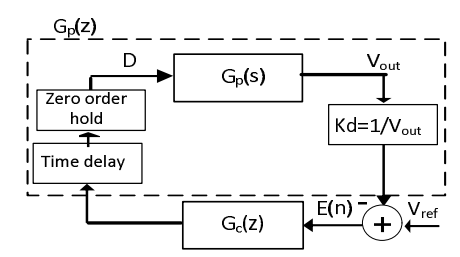

Fig.8. Digital Control Loop Block Diagram of Positive Buck-Boost Converter 
Since control-to-output-transfer function is a single pole transfer function, as illustrated in Fig. 8, to obtain a high loop gain at low frequencies and achieve desired regulation accuracy, its reciprocal into the PI controller's s-domain transfer function in (10), the digital PI controller's transfer function is given in (11).

$$
G_{P I}(\mathrm{z})=K_{p}+\frac{K_{i} \cdot T_{z}}{z-1}
$$

The recursive relationship between the output of the controller, i.e., control variable, and the input of the

controller, i.e., error signal that is implemented in the DSP is in (12.).

$$
C[k]=K_{p} e[k]+K_{i} T \sum_{i=0}^{k} e[i]
$$

Therefore, $\mathrm{C}[\mathrm{k}]$ is the controller output for the $\mathrm{k}_{\mathrm{th}}$ sample, and $\mathrm{e}[\mathrm{k}]$ is the error of the $\mathrm{k}_{\mathrm{th}}$ sample. The error $\mathrm{e}[\mathrm{k}]$ is calculated as $\mathrm{e}[\mathrm{k}]=\operatorname{Ref}-\mathrm{ADC}[\mathrm{k}]$, where $\mathrm{ADC}[\mathrm{k}]$ is the converted digital value of the $\mathrm{k}_{\text {th }}$ sample of the output voltage, and Reference of the digital value is corresponded to the output voltage. $\sum_{i=0}^{k} e[i]$ is the average errors and $\{\mathrm{e}[\mathrm{k}]-\mathrm{e}[\mathrm{k}-1]\}$ is the difference between the error $\mathrm{k}_{\mathrm{th}}$ sample and the error $(\mathrm{k}-1)_{\mathrm{th}}$ sample. The experimental results of the buck-boost converter using digital PI controllers is presented the block diagram for the equation (12) is shown in Fig.9.

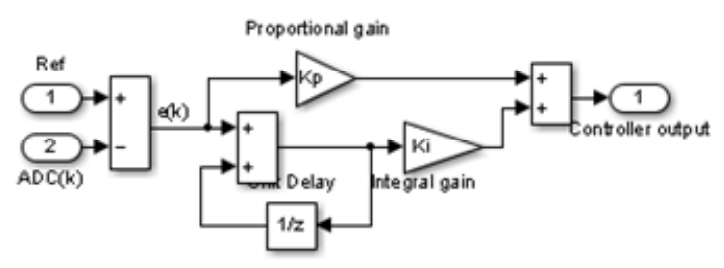

Fig.9. Block diagram of digital PI controller

\section{Simulation and Experimental results}

The positive buck-boost DC-DC converter of Fig. 10 is simulated with the parameters listed in Table I.

\section{TABLE 1. Simulation parameters}

\begin{tabular}{cc}
\hline Parameter & Value \\
\hline \hline & \\
Vin ,VDC & $60 \sim 200$ \\
\hline Vout, VDC & 110 \\
\hline Pout, W & 15000 \\
\hline $\mathrm{C}, \mu \mathrm{F}$ & $6800-250 \mathrm{vdc}$ \\
\hline $\mathrm{L}, \mu \mathrm{H}$ & 42 \\
\hline switching freq., $\mathrm{kHz}$ & 15 \\
\hline
\end{tabular}




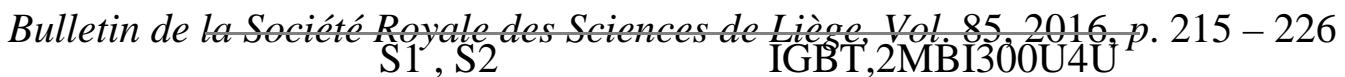

\begin{tabular}{cc}
\hline Efficiency & $92 \% @ 100 \%$ \\
\hline DSP & TM320F 28335
\end{tabular}

Simulations are achieved the positive buck-boost converter using the integrated methods in Fig 10.Fig 11 and Fig 12. presents the output voltage and output current waveform with time delay at zero, buck and boost pulses for a direct transition from buck to boost mode. There is about $1 \%$ ripple in the output voltage during direct transition from buck to boost. Fig.12.

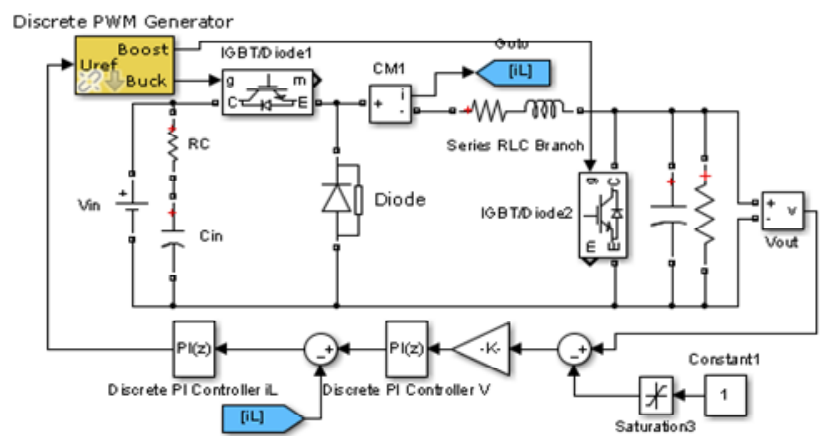

Fig.10. Dynamic model of the boost converter with double controller

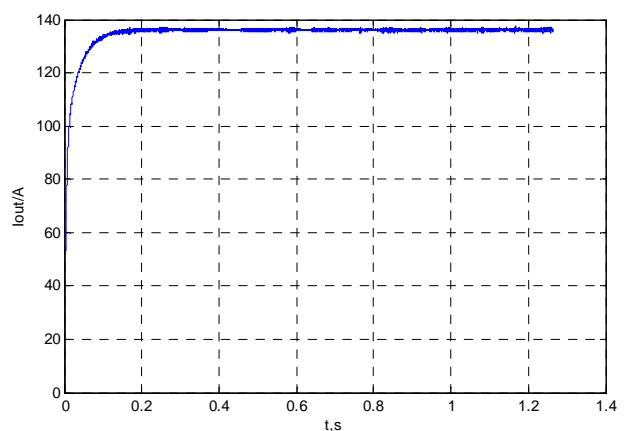

Fig.11. Waveform of output current in boost mode

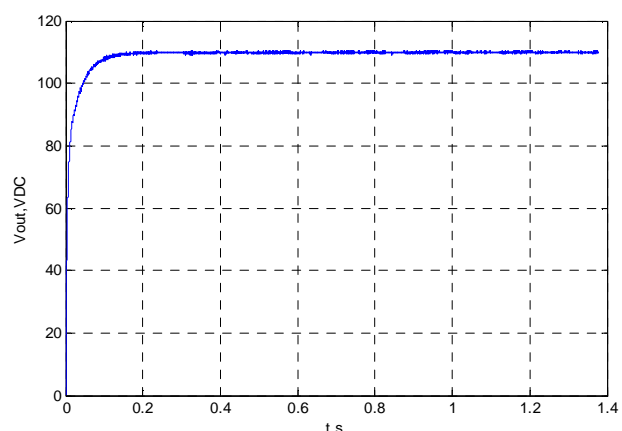

Fig.12. Response of output voltage in boost mode

The proposed controller has been tested on a boost prototype whose converter parameters are reported in Table I. The digital control has been implemented using a DSP (T320F28335). Fast A/D converters have been used, ensuring the conversion time to be slightly less than $1 \mu$ s. In our prototype the digital PWM has been organized as depicted in Fig. 14. Fig. 12 shows the converter behavior of boot operation in presence of step load variations from $11 \Omega$ to $0.8 \Omega$, and inductor current sensing give results very similar to those reported in Fig. 16. The results, presented in Fig. 17, shows that during DCM operation transient output voltage from boost to buck in full load recovery becomes much slower attributable to the error introduced by the estimation scheme which assumes CCM operation. 


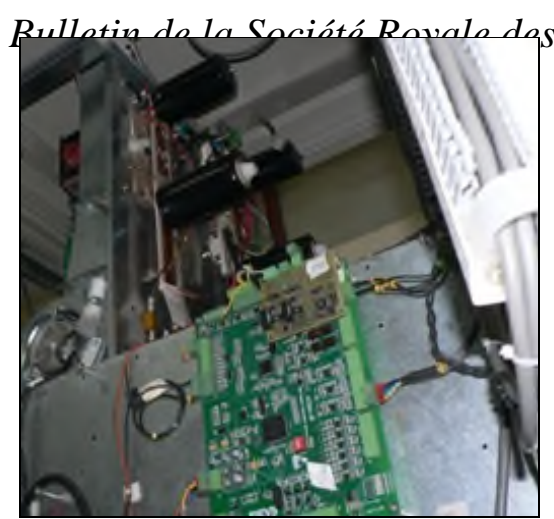

Fig.13. Figure of prototype with DSP (T320F28335) controller

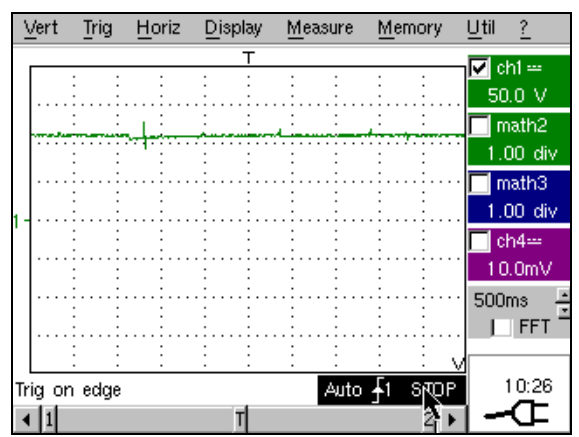

Fig.15. Step loud of out voltage in boost mode

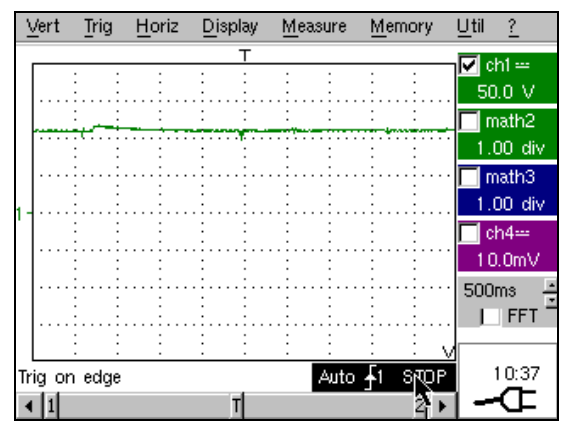

Fig.17. Transient output voltage from boost to buck in full load

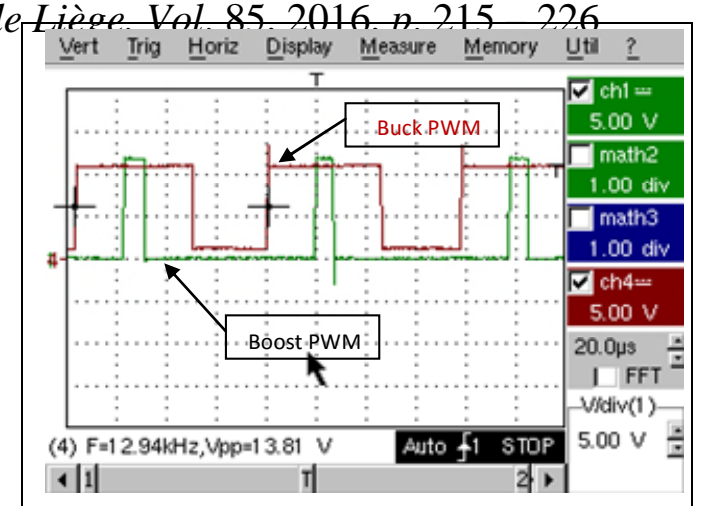

Fig.14.PWM generation of Buck and Boost

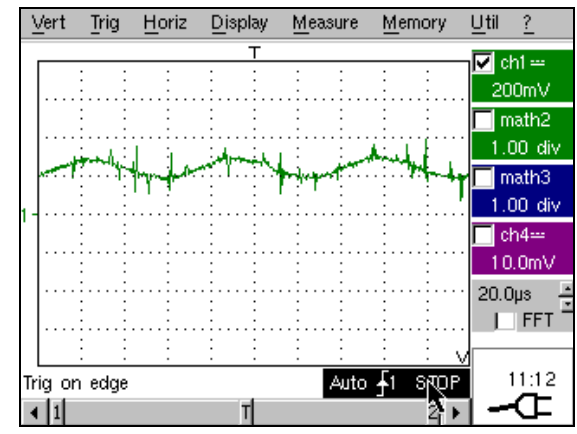

Fig.16. Waveform of Inductor current in boost mode

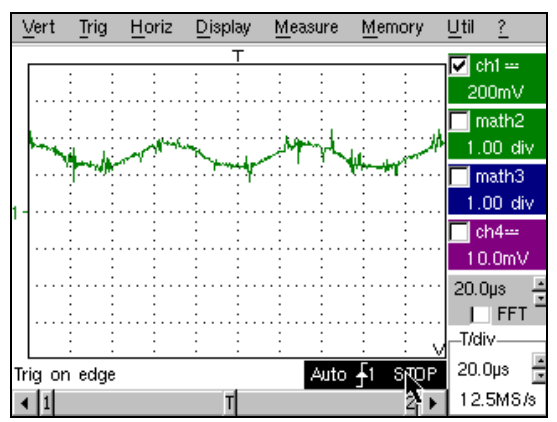

Fig.18. Waveform of inductor current in buck mode

\section{Conclusions}

DSP based digital integrated control system for industrial positive buck-boost DC-DC converter is investigated. The converter can be controlled in such a way that optimum efficiency is achieved under various operating points. The operating mode can also be shifted among continuous mode and discontinuous mode by changing the switching frequency. In addition, a digital controller could monitor the temperature of different parts of the converter to perform thermal management. Functions of control regulation, thermal management and supervision can all be integrated on a single DSP chip. Experimental results on a $15 \mathrm{~kW}$ dc-dc converter controlled by a DSP confirm the properties and limitations of the proposed approach. Finally 
Bulletin de la Société Royale des Sciences de Liège, Vol. 85, 2016, p. 215 - 226

control strategy proposed in this paper makes the cost lower and improves the conversion efficiency, which makes this strategy considerably cost-effective.

\section{References}

[1] Y. Lee, A. Khaligh, and A. Emadi, "A Compensation technique for smooth transitions in a non-inverting buck-boost converter," IEEE Trans. Power Electronics, vol. 24, no. 4, pp. 1002-1016, April 2009.

[2] Robert W. Erickson Dragan Maksimovic Fundamentals of Power Electronics, (2004 Kluwer Academic Publishers, New York, Boston, Dordrecht, London, Moscow.

[3] Y. He and F.L. Luo "Sliding-mode control for dc-dc converters with constant switching frequency" IEE Proc.-Control Theory Appl., Vol. 153, No. 1, an. 2006.

[4] E. Vidal-Idiarte, L. Martinez-Salamero, F. Guinjoan, J. Calvente and S. Gomariz "Sliding and fuzzy control of a boost converter usingan 8-bit microcontroller", Electric Power Applications, IEE Proceedings , On page(s): 5 - 11, 2004.

[5] Guoliang Cai, et al. "Adaptive Back stepping Control of the Uncertain Unified Chaotic System" International Journal of Nonlinear Science Vol.4 (2007) No.1,pp.17-24.

[6] Beccuti A.G., Papafotiou G., Morari M.; Aimer S., Fujioka H., Jonsson U., Integrated Control Techniques for Switched-Mode DC-DC Converters Part II: The Step-Up Topology.

[7] A.G. Beccuti,“ Integrated Control Techniques for Switched-Mode DC-DC Converters Part II: The Step-Up Topology”, Proceedings of the 2007 American Control Conference Marriott Marquis Hotel at Times Square USA,2007.

[8] J. Alvarez-Ramirez, I. Cervantes, G. Espinosa-Perez, P. Maya, A. Morales, “A Stable Design of PI Control for DC-DC Converters with an RHS Zero", IEEE Trans. on Circuits and Systems, Vol., Jan. 2001.

[9] Chin-Wei Chang and Chia-Ling Wei " Single-Inductor Four-Switch Non-Inverting BuckBoost DC-DC Converter ", IEEE 2011.

[10] B. Sahu, and G. A. Rincon-Mora, "A low voltage, dynamic, non-inverting, synchronous buck-boost converter for portable applications," IEEE Trans. Power Electronics vol. 19, no. 2, pp. 443-452, Mar. 2004.

[11] H. Xiao1 S. Xie," Interleaving double-switch buck-boost converter " IET Power Electron., Vol. 5, 2012. 
[12] .Roggia and F.Beltrame,J.Baggio, "Implementation Issues of a Digital Control System Applied to a PFC Boost Converter," IEEE,2009.

[13] R. Leyva and et al., "Passivity-Based Integral Control of a Boost Converter for Large-Signal Stability” IEEE Proc, Control theory Appl, Vol.153،No.2،March 2006.

[14] H.-K. Liao1 T.-J. Liang1, "Non-inverting buck-boost converter with interleaved technique for fuel-cell system" IET Power Electronics Journal, Vol 5,2012.

[15] Digital Control of Boost PFC AC-DC Converters with Predictive Control 14th International Middle East Power Systems Conference (MEPCON'10), 2010, Paper ID 273.

[16] P. Mattavelli. "Digital Control of dc-dc Boost Converters with Inductor Current Estimation" Power Electronics 9th Conference and Exposition, 2004.

[17] Goo-Jong Jeong et al., Application of Simple Adaptive Control to a DC/DC Boost Converter with Load Variation. 